BULLETIN Bulletin hispanique

HISPANIQUE Université Michel de Montaigne Bordeaux

118-2 | 2016

Varia

\title{
La propuesta ortográfica de la lengua española de Lorenzo Hervás y Panduro (1735-1809)
}

\section{Elena Battaner Moro}

\section{(2) OpenEdition}

1 Journals

Edición electrónica

URL: http://journals.openedition.org/bulletinhispanique/4645

DOI: 10.4000/bulletinhispanique.4645

ISSN: 1775-3821

Editor

Presses universitaires de Bordeaux

Edición impresa

Fecha de publicación: 15 diciembre 2016

Paginación: 673-692

ISBN: 979-10-300-0125-9

ISSN: 0007-4640

Referencia electrónica

Elena Battaner Moro, « La propuesta ortográfica de la lengua española de Lorenzo Hervás y Panduro (1735-1809) », Bulletin hispanique [En línea], 118-2 | 2016, Publicado el 15 diciembre 2019, consultado el 27 diciembre 2019. URL : http://journals.openedition.org/bulletinhispanique/4645 ; DOI : 10.4000/ bulletinhispanique.4645 


\title{
La propuesta ortográfica de la lengua española de Lorenzo Hervás y Panduro (1735-1809)*
}

\author{
Elena Battaner Moro \\ Universidad Rey Juan Carlos, Madrid
}

L'objet de cet article est de décrire la proposition de réforme de l'orthographe de la langue castillane exposée par Lorenzo Hervás y Panduro (1735-1809) dans son «École Espagnole de sourd-muets ou L’art de leur enseigner à écrire et parler la langue espagnole " (1795). L'article offre également des informations biographiques et bibliographiques permettant de comprendre les raisons théoriques et pratiques qui justifient la présence d'une réforme de l'orthographe dans un ouvrage destiné à l'instruction des sourds.

Mots-clés: histoire de la linguistique espagnole, Lorenzo Hervás y Panduro, réformes de l'orthographe.

El objetivo de este trabajo es describir la propuesta de reforma ortográfica de la lengua española que Lorenzo Hervás y Panduro (1735-1809) expuso en Escuela española de sordomudos o Arte para enseñarles a escribir y hablar el idioma español, dividida en dos tomos (1795). Asimismo da algunas indicaciones biográficas y bibliográficas que permiten comprender las razones teóricas y prácticas de la presencia de una reforma ortográfica en una obra dirigida a la instrucción de personas sordas.

Palabras claves: historia de la lingüística española, Hervás y Panduro, reformas ortográficas

The aim of this paper is describing the spelling reform of Spanish-Castillian language proposed by Jesuit scholar Lorenzo Hervás y Panduro (1735-1809) in his 1795 work on the education of the deaf-mute, entitled «Escuela española de sordomudos o Arte para enseñarles a escribir y hablar el idioma español, dividida en dos tomos». This article also offers some biographical and bibliographical data as well as the theoretical and applied

* Este trabajo forma parte del proyecto BICRES IV.2 (FFI2012-35364), que ha contado con financiación del Ministerio de Economía y competitividad. Deseo agradecer su ayuda y comentarios sobre este artículo a Jorge Castro, Noemí Pizarroso, Mercedes Quilis, M. ${ }^{a}$ José Martínez Alcalde y Miguel Ángel Esparza. 
reasons for understanding the presence of a spelling reform in a work intended for the instruction of deaf people.

Keywords: History of linguistics in Spain, Lorenzo Hervás y Panduro, Spelling reforms.

\section{INTRODUCCIÓN}

El jesuita Lorenzo Hervás y Panduro nació en Horcajo de Santiago (Cuenca, España) el 10 de mayo de 1735; estudió Filosofía y Teología en Madrid entre 1752 y 1760. Durante varios años, fue profesor de, entre otras materias, Metafísica y Geografía. En 1767 fue enviado al exilio italiano junto con sus compañeros de orden: vivió entonces en varios puntos de Italia, sobre todo en Cesena, hasta que en 1785 se mudó a Roma. Allí permaneció con distintos cargos hasta 1798, cuando se le obliga a regresar a Espańa. En 1801, debido a una segunda expulsión de los jesuitas, vuelve a Italia en 1802. Murió en Roma el 24 de agosto de 1809 .

La labor científica de Hervás da comienzo con la idea y la escritura de Idea dell'Universo (1778-1787, 1792), una obra de once tomos y veintiún volúmenes. Dividida generalmente en tres partes - Historia de la vida del Hombre, Elementos cosmográficos e Historia de las lenguas-, es esta última (vols. 17-21) la que le ha dado su fama como lingüista. En concreto, el volumen 17, que lleva por título Catalogo delle Lingue (1784) y que contiene una colección de lenguas del mundo conformada gracias a la información derivada de -entre otros-sus numerosos contactos con otros jesuitas misioneros que, como él, llegaban al exilio romano. Cuando Hervás se dispuso a traducir sus obras al español, el jesuita amplió y reestructuró algunos de sus textos. Dividió su Idea en cuatro obras relativamente independientes: Historia de la vida del hombre (Madrid, 1789-1799), Viaje estático al mundo planetario (Madrid, 1793-1794), El hombre físico, o anatomía humana físico-filosófica (1800) y Catálogo de las lenguas de las naciones conocidas (1800-1805).

Sin embargo, Escuela española de sordomudos o Arte para enseñarles a escribir y hablar el idioma español, dividida en dos tomos (en adelante, EES) es una obra totalmente independiente de este programa lingüístico, si podemos llamarlo así. Fue publicada en Madrid en 1795 en dos tomos (no se escribió en italiano); el primero se imprimió en la Imprenta Real y el segundo en la de Fermín Villapando. La EES fue publicada cuando Hervás todavía permanecía en el exilio italiano, por lo que fue escrita entre las ediciones italiana y española de Idea dell'Universo; de ello dan fe las citas cruzadas que aparecen en la edición en espańol y las diferentes referencias a sus obras que aparecen en la misma EES.

Hemos señalado antes que Hervás recaló en Roma en 1785. Gracias a su amistad con el abogado Pasquale di Pietro, el jesuita entró en contacto con los niños y jóvenes sordos que acudían a la pequeña escuela fundada por el sacerdote Tommaso Silvestri (1744-1789) ${ }^{1}$ en la tercera planta de la casa del

1. La obra de Silvestri, sin terminar, fue estudiada y transcrita por Alfonso Girolamo Donnino y publicada en Roma en 1889. Asimismo existen fragmentos manuscritos que se conservan en 
abogado Di Pietro, y que había comenzado a funcionar el 5 de enero de 1784. De hecho, el mismo Di Pietro también había colaborado para que Silvestri viajara a París entre enero y septiembre de 1783 y aprendiera, de primera mano, el método de instrucción a sordomudos desarrollado por Charles Michel de L'Épée (1712-1789)²: el objetivo era introducir el método en Italia y fundar las escuelas de instrucción a personas sordas.

Durante estos aproximadamente cuatro años (Silvestri murió, como L'Epée, en 1789), y siempre a través del italiano, Hervás conoció de primera mano los modos de instrucción y, por ende, todo lo relacionado con las personas sordas que, posteriormente, reconfiguró hacia lo lingüístico. Así, además de todo lo que de aplicado o rehabilitador o caritativo pudiera tener esta empresa, Hervás quedó fascinado por la trascendencia que para una «historia de la vida del Hombre» podía tener la existencia de lenguas de signos, de lenguas que no se hablan o, por extensión, de lenguas que no tienen nación o historia. Aunque la sordera era una cuestión que ya había tratado en algunas de sus obras, todo lo relacionado con ella comienza a tener carta de naturaleza en el programa del jesuita; y así, en cierto modo, reorganizará dicho programa para dar cabida a todas aquellas reflexiones -de índole médica, social, pedagógica, lingüísticaderivadas de su experiencia y de sus lecturas en torno a la instrucción de personas sordas (Battaner 2012).

En general, parece que una de las razones de que la Escuela Española de Sordomudos no haya sido tan estudiada en la historia de la lingüística española (v. Esparza et al. 2008 y Battaner 2009) puede deberse al hecho de que la investigación sobre Hervás se ha centrado habitualmente en aspectos del habla, de las lenguas o de la gramática. No obstante, contamos con un puñado de trabajos de distinta índole referidos a Escuela Española de Sordomudos, como los de Sánchez Pérez (1936), Corts \& García (1984), Poch (1999), Battaner (2011, 2012) y Battaner \& Dovetto (2013). En lo que se refiere a la ortografía, es conocido el hecho de que Hervás propone una reforma en su Escuela Española de Sordomudos (v. Esteve (1977) y otros trabajos generales referidos a la Ortografía o a la historia de la Ortografía de la lengua española (como Martínez Alcalde, 1999); el más reciente, Maquieira (2011)). No obstante, no hay un trabajo específicamente centrado en la propuesta ortográfica de Hervás, por lo que uno de los objetivos de este artículo es, precisamente, suplir esa falta.

\footnotetext{
la biblioteca del Istituto Statale per Sordi de esta ciudad italiana. El relato biográfico de Silvestri se encuentra también en esta obra. Para más información acerca de la relación entre Hervás y Silvestri, v. Battaner \& Dovetto (2013).

2. Charles Michel de L'Epée es conocido como uno de los primeros y más importantes maestros de personas sordas. Con cierta experiencia previa, a él se debe, en 1771, la fundación de la primera escuela oficial de instrucción a sordomudos. Muy influido, como es lógico, por la gramática general, L'Épée establece un método de instrucción basado en la seña o signo (los signos métodicos) con los que instruía a niños y jóvenes en su colegio. Adquirió fama y notoriedad -incluso Condillac asistió a sus lecciones-, y muchos maestros acudían a su colegio de París para aprender el método e importarlo en sus respectivos países.
} 
Publicada en 1776, la Institution des sourds et muets par la voie des signes méthodiques. Ouvrage qui contient le Projet d'une Langue Universelle, par l'entremise des Signes naturels assujettis à une Méthode (en adelante, Institution), escrita por Charles Michel de L'Épée, fue estudiada y seguida por Hervás en muchos aspectos - de forma y contenido-. Si bien el francés es conocido fundamentalmente por el desarrollo del método analítico y de la instrucción de personas sordas por medio de sus signos/señas metódicos, los capítulos $\mathrm{X}$ y XI de su Institution (titulados "Comment on peut apprendre aux Sourds \& Muets à parler» $\mathrm{y}$ "Observations nécessaires pour la lecture $\&$ la prononciation des Sourds \& Muets») están destinados a la enseñanza de la pronunciación. En esta obra, la enseñanza de la pronunciación comienza solo después de que los alumnos hayan aprendido a escribir la lengua francesa, cosa que ha ocurrido al mismo tiempo que se les ha ido instruyendo a través de las señas metódicas. Que los alumnos sepan leer es, por tanto, condición sine qua non-también en el caso de la Escuela de Hervás- para que pueda comenzarse la instrucción en la pronunciación de la lengua.

En estas circunstancias, como es lógico, los maestros que tratan de enseñar la pronunciación guiándose por las letras y por la escritura de una lengua tropiezan con la ortografía; y los alumnos, con el hecho de que las lenguas -en este caso, el francés o el español- no siguen, por así decirlo, el principio fonético. Estas dificultades fueron señaladas y descritas, enseguida, tanto por L'Epée como por Hervás. La principal diferencia entre ellos, no obstante, estriba en las medidas que ambos maestros tomaron al respecto: el francés solo dedicó unas notas a describir la diferencia entre la escritura y la pronunciación (v. cpto. XI de Institution); Hervás, en cambio, propuso directamente una reforma:

Nous avons soin de leur bien inculquer ce principe, que nous ne parlons pas comme nous écrivons. C'est un défaut de notre Langue; mais nous ne sommes pas maîtres de le corregir. (L’Epée 1776: 211)

El maestro tendrá gran dificultad en enseñarles los sonidos de las letras y sílabas, y no la tendrán menos en aprenderlos, si no conoce fundamentalmente la ortografía, con que se escriben las palabras espańolas, y los defectos de ella para corregirlos ó evitarlos del mejor modo que pueda. Á este fin despues en discursos separados trataré de la ortografía española, descubriré sus defectos claros y enormes, y propondré las industrias más útiles para su mejor suplemento ó correccion. (Hervás 1795: 194)

La reforma propuesta por Hervás se encuentra en la parte segunda del Tomo II de la $E E S$, titulada «Método práctico de enseñar el habla á los Sordomudos» ${ }^{3}$. En el primer capítulo de esta segunda parte, el jesuita realiza unas «Advertencias

3. La parte primera de este Tomo II está dedicada a la «enseñanza por escrito del idioma español». 
preliminares al método de enseñar el habla a los Sordomudos»; en él, entre otras cuestiones, apunta la necesidad de enseñar a leer antes que a pronunciar, sugiere la realización de exámenes médicos de los órganos de la voz y de la vista de los alumnos e indica cómo enseñar a manejar la voz. Hechas estas advertencias, Hervás titula el segundo capítulo "Ortografía española: sus defectos y correccion de ellos»; consta de apenas veinte páginas y puede entenderse como una transición hacia el capítulo III, que ya lleva por título «Breve idea del método práctico para enseñar á los Sordomudos la pronunciacion de los acentos vocales silábicos». Para entender las razones de que una reforma ortográfica se presente en estos términos es necesario detenernos un momento en los métodos de instrucción.

Los métodos de instrucción a personas sordas de siglos anteriores pueden situarse en algún lugar de un continuum entre dos polos: uno de ellos estaría representado por la instrucción a través de signos/señas (por ejemplo, la escuela francesa -aunque, como hemos visto, también dedica espacio a la pronunciación-); y el otro polo estaría representado por la instrucción mediante una lengua oral ${ }^{4}$ que, de manera tradicional, se ha asociado a una «Escuela española» (Battaner 2011). Hablamos de continuum porque nunca o casi nunca se presentan los métodos en estado puro y todos combinan, con mejor o peor fortuna, distintas formas de instrucción.

Una de las reformas pedagógicas más relevantes desarrolladas a lo largo del siglo XVIII tiene que ver con la forma de enseñar la lectura $-\mathrm{y}$, en el caso de las personas sordas, con la manera de enseñar la pronunciación-: para explicarlo brevemente, y aunque su historia completa es compleja y merece muchísima más atención de la que podemos prestarle aquí, se pasa de la enseñanza mediante el deletreo (o del nombre de las letras) a la enseńanza mediante sílabas: por ejemplo, la sílaba pa no se enseñaría como "pe $+\mathrm{a}=\mathrm{pa}$ " sino, directamente, "pa». De este modo, no habría que enseñar a pronunciar el problemático nombre de las letras (vocales y consonantes) y sus combinaciones, sino solo las combinaciones (vid. infra). Las ventajas de este procedimiento son numerosas, pero en lo que se refiere a la enseñanza de la pronunciación a personas sordas, aún lo son más. Este es uno de los aspectos más originales y novedosos de los métodos propuestos por L'Épée, Silvestri o Hervás. En lo que se refiere a la pronunciación, en sus obras podemos encontrar descripciones articulatorias como las siguientes 5

4. Los maestros de personas sordas más avanzados, como L'Épée o Hervás, sostenían sin ambages que la lengua de signos/señas era una lengua como tal y que era la lengua materna de las personas sordas. Entendían, por tanto, que el aprendizaje del francés o del español era equivalente a aprender una lengua extranjera. Asimismo indicaban que el instructor debía ser competente en lengua de signos/señas.

5. En Battaner \& Dovetto (2013) se describe la enseñanza de la pronunciación de vocales y consonantes (mediante sílabas) y se detiene en la descripción de dos procesos derivados de la coarticulación, como la epéntesis o la nasalización, como ejemplos del alcance fonético de las descripciones de estos autores. 
J'écris $b a, b e ́, b i, b o, b u$, parce que le $b$ n'est qu'un adoucissement du $p$. Pour faire entendre cette différence au Sourd \& Muet, je mets ma main sur la sienne ou sur son épaule, \& je la presse fortement, en lui faisant entendre que mes lèvres se pressent de même fortement l'une contre l'autre, lorsque je dis pa. Après cela je presse plus doucement sa main ou son épaule, $\&$ je fais observer que mes lèvres se pressent aussi plus doucement en disant $b a$. Le Sourd \& Muet pour l'ordinaire fait cette différence, $\&$ il prononce $b a, \&$ tout de suite bé, bi, bo, bu. (L'Epée 1776: 198)

El maestro escribirá la sílaba $b a$, la mostrará al Sordomudo, y la pronunciará despacio algunas veces para que el discípulo observe bien la configuracion de los labios, y con su mano sienta la impresion del aliento, y del movimiento de los organos vocales al pronunciarla. En la pronunciacion de la silaba $b a$, los labios se separan delicadamente, y no repentinamente. (Hervás 1795: 226)

Por tanto, si la enseñanza de la pronunciación se va a basar en las sílabas y estas sílabas son las combinaciones de letras que se encuentran en la escritura, llegamos ineludiblemente a los problemas que plantean los sistemas ortográficos de lenguas como la española o la francesa. Puesto que hay ciertas inconsistencias en la forma de pronunciar y escribir algunas letras o combinaciones de letras y sonidos (en español, por ejemplo, b/v, c/z, g/j, h, etcétera), bien porque varias letras representen un mismo sonido, bien porque una letra represente varios sonidos -entre otros-, estos maestros se encuentran con una complicación específicamente práctica en la enseñanza de la pronunciación; y al contrario, este es el problema que existe, en el caso de personas oyentes, con la enseñanza de la escritura. Sin embargo, el proceso es diferente en el caso de las personas sordas: no se llega de lo oral a lo escrito, sino de lo escrito a lo oral. Para los maestros de sordomudos, entonces, la simplificación ortográfica -léase reforma- era más necesaria que nunca.

\section{Las ideas ortográficas de Lorenzo Hervás y Panduro}

Puesto que Lorenzo Hervás y Panduro escribió notables y variadas obras acerca del lenguaje y de las lenguas, es evidente que una cuestión como la ortográfica puede encontrarse en varios lugares de su trabajo y debido a motivos de todo tipo: en la EES aparece, por ejemplo, en relación con el método de instrucción de la pronunciación; pero en el Catálogo hay reflexiones ortográficas de todo tipo a propósito de letras, abecedarios, voces y sonidos de lenguas y familias de lenguas; y en Historia de la vida del Hombre, cuando expone sus planteamientos acerca de la instrucción de niños y niñas y de la enseñanza de la lectura, también incluye comentarios específicamente ortográficos. Pero la ortografía no será en ningún momento un objeto único de trabajo: en Hervás no encontraremos, como es lógico, un planteamiento sistemático equivalente a los que aparecen en todas aquellas obras consideradas ortográficas -o gramaticales- en sí.

De este modo, es necesario tener en cuenta que la naturaleza del pensamiento ortográfico de Hervás es esencial y fundamentalmente aplicada, por lo que no encontraremos -al menos de forma explícita-consideraciones generales de tipo 
teórico. Dentro de estas consideraciones podríamos incluir, por ejemplo, la discusión acerca de si la ortografía es o no una parte de la gramática o cuáles son las disciplinas en las que puede dividirse la ortografía (ortología ${ }^{6}$, prosodia...). Y pese a sus opiniones -a veces poco claras-al respecto, Hervás tampoco defiende o abandera, por poner otro ejemplo, una posición definitiva en relación con el empleo del criterio etimológico o de uso a la hora de utilizar una grafía u otra.

Sin embargo, y como no podía ser de otra manera, el carácter aplicado de sus reflexiones condiciona absolutamente su posición ortográfica hacia el criterio de la pronunciación. Y creo que es importante señalar que, en mi opinión, y aunque Hervás conocía las tradiciones de todo tipo -médicas, jurídicas, históricas, lingüísticas...- y su erudición es antológica, no es menos cierto que, hasta determinado punto, el jesuita no conocía a fondo la situación de la ortografía en la España contemporánea.

Pese a todo lo anterior, sí podemos encontrar ideas concretas o particulares referidas a distintos hechos ortográficos más precisos, como la definición de sonido, voz o letra, entre otros; por ejemplo:

El habla es la voz, ò es un acento sonoro; ó es el sonido que hace el ayre respirado por el hombre, y modificado en su garganta, y en su boca [...] Se escribe [el ayre sonoro], pinta, ó figura denotando con cierto número de símbolos, cifras, ó letras igual número de acentos vocales, que hay, y se distinguen en el habla de un idioma [...] Por convención arbitraria, que los hombres han hecho de figurar un determinado acento con una determinada cifra, ò letra, los idiomas se escriben [...] (Hervás 1795: 5; v. Maquieira 2011)

Sin embargo, en lo que se refiere a la lengua española y a su abecedario, Hervás había señalado ya lo siguiente:

[...] el órden de las letras no corresponde con el que naturalmente deben tener, segun la mayor ó menor facilidad en pronunciarlas. Las vocales, que son las letras mas fáciles de pronunciar, debian ser las primeras del abecedario. Despues de las vocales debian seguir las consonantes labiáles b, m, p: despues de éstas debian seguir las dentales d, t, \&c. Mas este desórden en las letras no es gran mal; el mayor está en la denominacion que se da á cada consonante. (Historia de la Vida del Hombre, Libro II, Capítulo IX; pág. 296 y ss.)

Pero de nuevo el carácter aplicado de sus ideas ortográficas asoma en lo que se refiere a la clasificación de los sonidos -esencialmente articulatoria-y al peso que otorga a una entidad como la sílaba (v. infra):

6. Pese a que este tomo de la Escuela Española de Sordomudos está dedicado a la enseñanza de la pronunciación, creo que no debe confundirse, por muchas razones, con una ortología. Una de ellas es que Hervás ofrece, en algunos casos, indicaciones acerca de cuál debe ser la "correcta» pronunciación; pero en otros, lo estrictamente práctico puede llegar a pesar más que lo normativo; véase, por ejemplo, la siguiente indicación: «La letra $m$, sin notable disonancia en el acento, se puede pronunciar como $n$ en las palabras embargar, embiar, empezar, imposible, importuno, ombre, ombro, umbral, \&c. por lo que á los Sordomudos se enseñará a pronunciar la sílaba an, y no la sílaba am.» (Hervás 1795: 204). 
Después que el discípulo Sordomudo sepa pronunciar las vocales, y tenga algún hábito en ello, empezará á aprender la pronunciacion de las sílabas, y entre estas las primeras que aprenderá serán las sílabas ba, pa, ma, por ser las más fáciles de pronunciar. (Hervás 1795: 225)

No obstante el carácter aplicado que he mencionado, también es cierto que este únicamente se reduce a la pronunciación de sonidos escritos mediante letras y que su método se centra estrictamente en ello: así, no hay en ningún caso apuntes prosódicos -entendidos como los clásicos suprasegmentales(poco o nada acerca del acento o entonación, por ejemplo) y, desde luego, ninguna mención a la puntuación. Por tanto, es muy posible que hablar de la «Ortografía de Hervás» sea excesivo y que a este respecto podemos referirnos, simplemente, a unos apuntes o ideas sobre ortografía o, más concretamente, a una propuesta ortográfica.

\section{La propuesta ortográfica de Lorenzo Hervás y Panduro}

El plan ortográfico de Hervás se halla, por tanto, en el capítulo II del Tomo II, y lleva por título "Ortografía espańola: sus defectos y correccion de ellos» (p. 199 y ss.). Como se ha señalado antes, aparece entre las advertencias antes de comenzar la instrucción de la pronunciación y la instrucción misma, que tenía como objeto «introducir la nueva [ortografía] con que el mas idiota que supiese escribir, pudiese escribir bien, escribiendo como habla» (Hervás 1795: 208).

Comienza Hervás el capítulo explicando las razones -filológicas, más a modo del Catálogo- de las deficiencias ortográficas del español:

En la ortografia de la escritura española, como tambien en la de la escritura de la mayor parte de las lenguas europeas, hay defectos enormes [...] Tales defectos ortográficos provienen de no tener muchas naciones europeas el número, y la calidad de letras que convienen ó se necesitan para espresar ó denotar los respectivos o proprios acentos vocales de sus lenguas. El español, por exemplo, que antiguamente hablaba el idióma cantabro o vascongado, lo abandonó para hablar el latino; mas no abandonó la pronunciacion bascongada, con la que profiere las palabras latinas de su idioma actual; y la dicha pronunciacion hizo servir el alfabeto que los romanos usaban, para pronunciar las palabras de su lengua latina. Este alfabeto que se habia formado segun la variedad, y el número de los acentos vocales de la lengua latina, no podia enteramente convenir á la pronunciacion de los acentos vocales vascongados, si éstos eran diferentes (como lo son) de los latinos en el número, y en la calidad: mas no obstante esto, los españoles adoptaron y usan el alfabeto latino sin reformar las letras que en él hay inútiles a su pronunciación, y por esto su ortografía es defectuosa. Esto mismo sucede á todas las naciones européas (menos la italiana, la ilirica, y la griega) porque han adoptado letras forasteras que les son superfluas, ó no han inventado las necesarias para sus respectivas pronunciaciones. (Hervás 1795: 199-200). 
En esta línea, Hervás también hablará de la imperfección de los alfabetos de lenguas y naciones consideradas «doctas», de forma que "las naciones alemana, inglesa, sueca, dinamarquesa, francesa y española, que son doctas, usan todavía de alfabetos imperfectos, que adoptaron en tiempo de su ignorancia: conocen y confiesan su imperfeccion, y no la remedian» (Hervás 1795: 208-209). Así -y a diferencia de L'Épée- Hervás ofrecerá, en las líneas que siguen, dicho remedio. Para ello, comienza con la descripción de los sonidos y letras de la lengua española.

\section{Los sonidos y las letras de la lengua espańola}

En palabras de Hervás, el maestro de sordomudos debe conocer «el número de las pronunciaciones, ó de los acentos vocales de la lengua española, y el de las letras necesarias y superfluas». A continuación propone una "tabla alfabética de las pronunciaciones españolas con algunas observaciones sobre ésta» ${ }^{7}$ (pp. 200201) que reproduzco en la tabla 1 (incluyo los símbolos fonéticos equivalentes a los sonidos atribuidos a las letras).

Pronunciaciones españolas.

Su número

$\begin{array}{lccccccc}\text { Vocales } & \text { a. } & \text { e. } & \text { i. } & \text { o. } & \text { u. } & & 5 \\ & \text { ba. } & \text { be. } & \text { bi. } & \text { bo. } & \text { bu. } & {[\mathrm{b}]} & 1 \\ \text { Sílabas labiales } & \text { pa. } & \text { pe. } & \text { pi. } & \text { po. } & \text { pu. } & {[\mathrm{p}]} & 1 \\ & \text { ma. } & \text { me. } & \text { mi. } & \text { mo. } & \text { mu. } & {[\mathrm{m}]} & 1 \\ & & & & & & & \\ \text { Labiodentales } & \text { va. } & \text { ve. } & \text { vi. } & \text { vo. } & \text { vu. } & {[\mathrm{b}, \beta]} & 1 \\ & \text { fa. } & \text { fe. } & \text { fi. } & \text { fo. } & \text { fu. } & {[\mathrm{f}]} & 1 \\ & \text { da. } & \text { de. } & \text { di. } & \text { do. } & \text { du. } & {[\mathrm{t}]} & 1 \\ \text { Dentales } & \text { ta. } & \text { te. } & \text { ti. } & \text { to. } & \text { tu. } & {[\mathrm{t}]} & 1 \\ & \text { za. } & \text { ze. } & \text { zi. } & \text { zo. } & \text { zu. } & {[\theta]} & 1\end{array}$

7. Es interesante recalcar que la exposición de las pronunciaciones no sigue el orden alfabético tradicional (excepto por las series $\mathrm{a}-\mathrm{u}$ ): como vemos, responde a criterios articulatorios (i.e. punto de articulación, de la parte anterior a la posterior) que, para Hervás, respondían al grado de facilidad en la pronunciación de las consonantes: así, las anteriores son más fáciles de pronunciar que las posteriores. Se trata, no obstante, de una presentación que no es novedosa ni en la obra de Hervás ni en la de sus contemporáneos. 


$\begin{array}{cccccccc} & \text { la. } & \text { le. } & \text { li. } & \text { lo. } & \text { lu } & {[\mathrm{l}]} & 1 \\ & \text { na. } & \text { ne. } & \text { ni. } & \text { no. } & \text { nu. } & {[\mathrm{n}]} & 1 \\ \text { ya. } & \text { ye. } & \text { yi. } & \text { yo. } & \text { yu } & {[\mathrm{y}]} & 1 \\ \text { lla. } & \text { lle. } & \text { lli. } & \text { llo. } & \text { llu. } & {[\Lambda]} & 1 \\ & \text { ña. } & \text { ñe. } & \text { ñi. } & \text { ño. } & \text { nu } & {[\mathrm{n}]} & 1 \\ & \text { sa. } & \text { se. } & \text { si. } & \text { so. } & \text { su. } & {[\mathrm{s}]} & 1 \\ & \text { ra. } & \text { re. } & \text { ri. } & \text { ro. } & \text { ru. } & {[\mathrm{r}]} & 1 \\ & \text { ka. } & \text { ke. } & \text { ki. } & \text { ko. } & \text { ku. } & {[\mathrm{k}]} & 1 \\ & \text { ga. } & & & \text { go. } & \text { gu. } & {[\mathrm{g}]} & 1 \\ & \text { ja. } & \text { je. } & \text { ji. } & \text { jo. } & \text { ju. } & {[\mathrm{x}]} & 1\end{array}$

Tabla 1. «Tabla alfabética de las pronunciaciones españolas con algunas observaciones sobre ésta» de Hervás y Panduro (1795)

Según Hervás, a estas 23 pronunciaciones hay que sumar la de la letra ch [ts] y la de la letra r (como [r]; la vibrante múltiple ya está incluida en la tabla anterior), lo que haría un total de 25 pronunciaciones:

Estas son las 23 pronunciaciones que tiene la lengua española. Á las que se deben añadir dos pronunciaciones; una que se dá á las sílabas cha, che, chi, cho, chu, [ts] y otra que se dá á las sílabas ra, re, ri, ro, ru, [r] quando en una misma diccion les precede vocal, como en las palabras amára, amaré, amaría, amáron. En estas y en otras palabras semejantes, la pronunciacion de las sílabas ra, re, ri, ro, ru por su suavidad se distingue claramente de la pronunciacion de las mismas sílabas, quando son iniciales, ó estando en medio de diccion no les precede vocal. Al fin de las dicciones, la letra r se pronuncia siempre con suavidad, como en amar, amor, \&c. Añadiéndose esta pronunciacion suave de la letra r á las demás pronunciaciones de la lengua española, éstas serán veinte y cinco. (Hervás 1795: 201)

Por tanto, son las pronunciaciones que, en primer lugar, deben enseñarse a los Sordomudos. Como vemos, no se trata de enseñar a pronunciar las «letras» a través de su nombre (a, be, ce, de, efe, ge...), sino de pronunciar su sonido acompañado de una vocal (ba, be, bi, bo, bu). Una vez que el alumno conoce las veinticinco pronunciaciones, puede seguir aprendiendo el resto de combinaciones silábicas ${ }^{8}$. Solo después «se les hará conocer que á ellas pertenecen las pronunciaciones de otras sílabas que se usan en la escritura española, y se diferencian de las expuestas en las letras y no en el sonido» (Hervás 1795: 201); es decir, los problemas de coherencia ortográfica. Comienza entonces el jesuita

8. No obstante lo anterior, más adelante Hervás describirá la pronunciación de cada sonido de uno en uno, nunca en combinación silábica. Lo que sí hace después es describir la enseñanza de la pronunciación de otras combinaciones silábicas (donde aparecen problemas coarticulatorios). V. Battaner \& Dovetto (2013). 
la relación de problemas ortográficos de la lengua española; o, por decirlo de otra manera, la relación de los desajustes entre escritura y pronunciación:

El maestro, pues, despues de haberles dado á conocer el valor de las 25 sílabas espuestas, les pondrá á la vista las dos lineas de las siguientes sílabas.

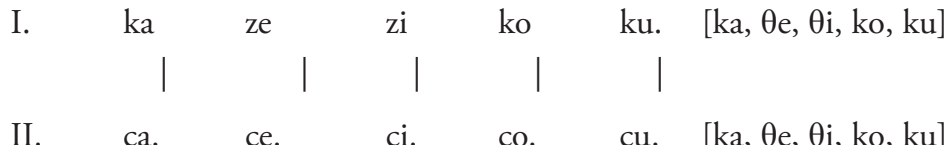

Hará el maestro que pronuncien las sílabas de la primera linea con este órden. Pronunciarán primeramente la sílaba ka; y despues el maestro les hará saber que la sílaba ca se debe pronunciar como la sílaba ka. De este modo se les hará saber que la sílaba ce, tiene el mismo sonido que la sílaba ze: que ci se pronuncia como la sílaba zi, \&c.

Con la misma industria el maestro hará conocer á los Sordomudos, que son semejantes las pronunciaciones de las sílabas siguientes, que se combinan ó unen con una linea.

$\begin{array}{ccccc}\text { ka ke } & \text { ki } & \text { ko } & \text { ku. } & {[\mathrm{ka}, \mathrm{ke}, \mathrm{ki}, \mathrm{ko}, \mathrm{ku}]} \\ \text { qua. } & & & \end{array}$

Grafía antigua

\begin{tabular}{|c|c|c|c|c|c|}
\hline ja & je & ji & jo & ju & {$[\mathrm{xa}, \mathrm{xe}, \mathrm{xi}, \mathrm{xo}, \mathrm{xu}]$} \\
\hline xa. & xe. & xi. & xo. & $\mathrm{xu}$. & {$[x a, x e, x i, x o, x u]$} \\
\hline & \multicolumn{5}{|c|}{ Grafía antigua } \\
\hline & ge & gi & & & \\
\hline
\end{tabular}

Despues que el maestro haya enseñado la pronunciacion de las dicciones disílabas, que empiezan con consonante, enseñará las de las que empiezan con vocal seguida de un consonante, que con ella se pronuncia, como en las siguientes dicciones.
al. am. an. ar. as.
el. em. en. er. es.
il. im. in. ir. is.

(Hervás 1795: 201)

Puesto que la enseñanza se lleva a cabo mediante las sílabas de la lengua, es necesario realizar un inventario de dichas sílabas y de sus formas o combinaciones posibles en la lengua española. No es fácil encontrar esta relación -o siquiera una definición de sílaba- en la obra de Hervás: por lo que se desprende de sus páginas, el concepto de sílaba simplemente aludiría al agrupamiento de 
letras (no necesariamente de sonidos), de forma que podemos hallar «dicciones disílabas» para las combinaciones CV y VC o «dicciones trisílabas» para CVC y CCV, entre otras. Esta noción de sílaba es más evidente en el caso de las siguientes, que Hervás denomina "dicciones trisílabas»:

Á las dicciones trisílabas pertenecen las siguientes.

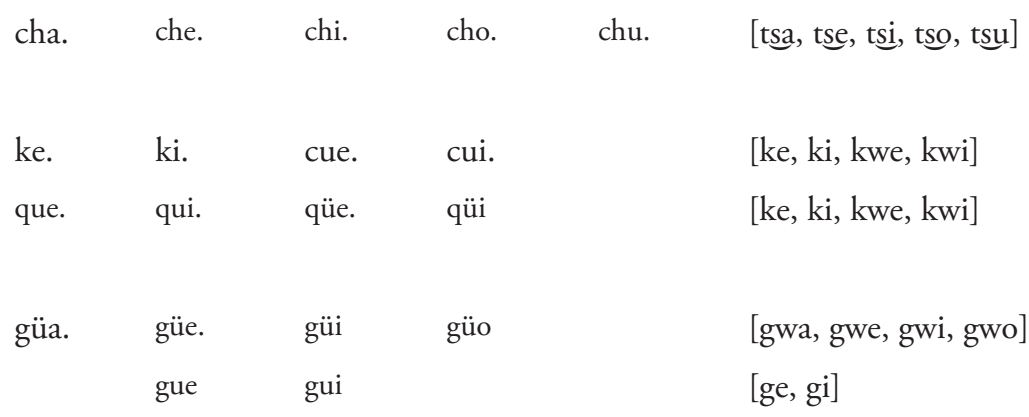

(Hervás 1795: 205)

Evidentemente, se trata de una concepción clásica de la sílaba. Asimismo, en otras páginas, el jesuita también ha señalado el hecho de que es necesaria la presencia de una vocal para que haya una sílaba y más adelante incluirá la necesidad de que deben ser emitidas en un golpe de voz?

Al hilo de las cuestiones ortográficas relacionadas con la pronunciación, creo que es interesante incluir la siguiente cita: en ella, el jesuita realiza diferentes observaciones acerca de las sílabas. Antes he señalado que Hervás no realiza exactamente un inventario de sílabas o de combinaciones de sonidos posibles $^{10}$ en la lengua española (como sabemos, y a diferencia del jesuita, no todas las combinaciones son posibles), por lo que esta cita ayuda a acotar las posibilidades. Nótese de nuevo cómo apela el jesuita a la facilidad o no de enseñar determinadas combinaciones silábicas:

9. Esta característica será evidente cuando trate de corregir la pronunciación de determinadas sílabas y algunos efectos de la coarticulación, como la aparición de vocal esvarabática en sílabas de ataque complejo (pra, pre, pla, etc.) (v. Battaner \& Dovetto, 2013). En la siguiente cita podemos encontrar otro ejemplo referido a las sílabas cerradas sin ataque: «Ellos [los alumnos] tardan en pronunciar estas sílabas, pues pronuncian siempre una vocal despues de las consonantes: así dicen ala, ale, ama, \&c. Para que conozcan que en las dichas sílabas no se ha de pronunciar ninguna vocal despues de las consonantes, el maestro con prontitud les pondrá la mano en la boca al acabar de pronunciar la consonante, que se une con la vocal antecedente. Por exemplo, si un Sordomudo pronuncia la sílaba am; despues que pronuncie la vocal $a$, y al cerrar los labios, y empezar la pronunciacion de la consonante $m$, el maestro le pondrá un dedo en su boca para que no prosiga la pronunciacion, ó le hará señal visible para que cese de pronunciar.» (Hervás 1795: 203).

10. Podemos decir que, en cierto modo, sí lo hace: será más adelante, cuando explique paso por paso y punto por punto la enseñanza de la pronunciación de las diferentes combinaciones silábicas. En Battaner \& Dovetto (2013) se señala que el orden de enseñanza de las sílabas en Hervás está literalmente tomado de la propuesta de Silvestri. 
Sobre la pronunciacion de las dichas sílabas, el maestro tendrá presentes las dos [serán tres] advertencias siguientes: I. Por ser difícil de pronunciar éstas sílabas, el maestro podrá enseñar su pronunciacion, despues que estén prácticos en pronunciar las dicciones disílabas y trisílabas fáciles, quales son las que empiezan con consonante. II. En español hay pocas consonantes, que se pronuncien con la vocal inicial de las palabras; tales consonantes suelen ser $\mathrm{l}, \mathrm{m}, \mathrm{n}, \mathrm{r}, \mathrm{s}$ : de estas las comunes son $\mathrm{n}, \mathrm{r}, \mathrm{s}$. La letra $\mathrm{m}$, sin notable disonancia en el acento, se puede pronunciar como $\mathrm{n}$ en las palabras embargar, embiar, empezar, imposible, importuno, ombre, ombro, umbral, \&c. por lo que á los Sordomudos se enseńará a pronunciar la sílaba an, y no la sílaba am. La mayor parte de las palabras espańolas que empiezan con la sílaba al, en la que la 1 se pronuncia con la a, son de origen arábigo. Se usan en español algunas palabras $\mathrm{ab}$, ad (en las que las consonantes se pronuncian con la vocal a); mas éstas palabras son pocas, y conservan aún la ortografia latina, que el español ha abandonado. II[I]. Aunque en español no se usan las sílabas ad, ed, id, od, ud, en las que la d se pronuncia con la vocal precedente, mas se usan muchas palabras, que acaban en ad, ed, id, y algunas que acaban en ud, como bondad, verdad, caridad, amad, enseñad, \&c. sed, merced, tened, vended, \&c. vid, ardid, oid, \&c. virtud, gratitud, \&c. por lo que los Sordomudos deben aprender la pronunciacion de las sílabas ad, ed, id, ud. La sílaba final ul rarísima vez se usa en la lengua española: poquisimas veces la sílaba final ol (que el Sordomudo debe aprender, para que lo menos sepa decir que es español) y muchas veces se usan las sílabas finales al, el, il, como en cal, mal, sal, metal, \&c. miel, papel, laurel, \&c. vil, civil, pueril, \&c.

Despues que sepan pronunciar las dicciones disílabas, aprenderán la pronunciacion de las trisílabas, entre las que no son difíciles de pronunciar las que empiezan y acaban con consonante, como ban, ben, dan, den, fan, fen, pan, \&c. De estas ultimas sílabas de pronunciacion difícil el maestro elija las que se usan en español: en éste son no poco comunes las sílabas iniciales fre, gra, pre, pri, pro, tra, tre, tri: se usan en algunas palabras las sílabas bla, ble, blo, bra, bre, bri, bro, bru, cla, cle, cre, cri, cru, fla, fle, flo, fri, fru, glo, gre, gri, gro, gru, pla, ple, tro: poquísimas veces se usan las sílabas flu, gla, plo, plu, pru. El maestro, según ésta noticia del mayor ó menor uso de las sílabas espuestas, instruirá á sus discípulos en la pronunciacion de ellas. (Hervás 1795: 203205)

\section{La propuesta ortográfica de Hervás y Panduro}

Una vez señaladas y descritas las que, para Hervás, eran las pronunciaciones de la lengua española, y habiendo hecho diferentes observaciones al respecto (recordemos que la enseńanza de la pronunciación real de estas sílabas comenzará en el capítulo siguiente de la EES), el jesuita entra de lleno en la reflexión puramente ortográfica: entonces vuelve la vista hacia las letras que él denomina «inútiles» $(\mathrm{b}, \mathrm{k}, \mathrm{q}, \mathrm{x}, \mathrm{h})$, lo que le permitirá introducir su propuesta de reforma ortográfica:

A la menor reflexion que se haga sobre el silabario propuesto y sobre las breves observaciones que se han hecho, se conocerá claramente el número de letras que inutilmente se usan en la ortografía espańola, y el facilísimo modo de dar á esta la mayor perfeccion para que todos escriban y aprendan facilísimamente á escribir las palabras españolas con uniformidad, y del modo que se pronuncian. 
Las letras, totalmente inútiles á la ortografía y á la pronunciacion de la lengua española son b, k, q, x [falta la hache]: y si en la educacion privada de las casas, y en la pública de las escuelas no se procura introducir la pronunciacion que á la letra b dan las demás naciones europeás, esta letra se debe desterrar, como inútil del alfabeto espańol; pues en toda España las letras b, v se profieren con un mismo acento, el qual suena mas como v que como b.

La letra h es inútil, porque segun la pronunciacion castellana, que es comun en España y en la América española, no suena jamás en las palabras: ni es justo que suene, pues el sonido de éstas, en tal caso, sería gutural y ofensivo al oido delicado, como lo es el acento gutural, que los Árabes enseñaron en España darse á la dicha letra. Las naciones francesa, italiana, \&c. no dan ningun sonido á la letra h.

La letra k es inútil, quando á las sílabas ce, ci se les den sonidos semejantes á los que tienen las sílabas ke, ki; y para que el lector distinga las palabras en que las sílabas ce, ci tendrán el sonido de ke, ki, sobre la c se pone una rayita asi c̃: y con esta rayita se significará que la c conserva su valor propio, y no el que por abuso se le ha dado hasta ahora. De este modo todos al ver escritas estas sílabas c̃e, c̃i, proferirán sin equivocacion alguna los sonidos que se dan á las sílabas ke, ki: así como despues que en el alfabeto español se ha introducido la letra ń, todos, al ver las sílabas ña, ñe, ñi, les dan su sonido propio y diferente del que dan á las sílabas ne, ni.

La misma industria se debe usar con la letra g, sobre la qual, quando esté delante de las vocales e, i, se pondrá una rayita para denotar que no se debe pronunciar con acento gutural, como actualmente se pronuncian las sílabas ge, gi, sino con el acento algo palatino con que actualmente se pronuncian las sílabas ga, gue, gui, go, gu.

Con las dichas industrias fáciles, y que poco alteran la actual escritura española, los acentos vocales, que actualmente se escriben con las sí labas ce, ci, se escribirán siempre con las sílabas ze, zi; y los acentos vocales que actualmente se escriben con las sílabas ge, gi, se escribirán con las sílabas je, ji. Dándose el sonido uniforme á las sílabas ca, $\tilde{\mathrm{ce}}, \tilde{\mathrm{c} i}, \mathrm{co}, \mathrm{cu}$, serán totalmente inútiles las letras k, q.

La letra $\mathrm{x}$ es inútil en espańol, porque unas veces se pronuncia como la jota, y otras se pronuncia como las letras cs. En el primer caso se usará la jota en su lugar; y en el segundo se usarán las letras cs. (Hervás 1795: 206-207)

En la tabla 2 resumo la aportación de Hervás. En la columna de la izquierda se muestra la forma de la escritura entonces; la segunda columna apunta la realización fonética de la escritura; la tercera incluye la propuesta de escritura del jesuita -en función de la pronunciación-; y la cuarta y última columna sugiere la que, en general, pudiera ser la opción más «sencilla».

\begin{tabular}{|c|c|c|c|}
\hline Escritura & $\begin{array}{c}\text { Transcripción } \\
\text { fonética }\end{array}$ & Propuesta de Hervás & $\begin{array}{c}\text { Solución más } \\
\text { sencilla }\end{array}$ \\
\hline $\begin{array}{c}\text { ba, be, bi, bo, bu } \\
\text { va, ve, vi, vo, vu }\end{array}$ & [ba, be, bi, bo, bu $]$ & va, ve, vi, vo, vu & $\begin{array}{c}\text { cualquiera } \\
\text { (b o v) }\end{array}$ \\
\hline
\end{tabular}




\begin{tabular}{|c|c|c|c|}
\hline Escritura & $\begin{array}{l}\text { Transcripción } \\
\text { fonética }\end{array}$ & $\begin{array}{c}\text { Propuesta de } \\
\text { Hervás }\end{array}$ & $\begin{array}{c}\text { Solución más } \\
\text { sencilla }\end{array}$ \\
\hline ca, que, qui, co, cu & {$[\mathrm{ka}, \mathrm{ke}, \mathrm{ki}, \mathrm{ko}, \mathrm{ku}]$} & $\mathrm{ca}, \tilde{\mathrm{ce}}, \tilde{\mathrm{c}} \mathrm{i}, \mathrm{co}, \mathrm{cu}$ & $\mathrm{ca}, \mathrm{ce}, \mathrm{ci}, \mathrm{co}, \mathrm{cu}$ \\
\hline za, ze/ce, zi/ci, zo, zu & {$\left[\theta \mathrm{a}, \theta \mathrm{e}, \theta \mathrm{i}, \theta_{\mathrm{o}}, \theta_{\mathrm{u}}\right]$} & za, ze, zi, zo, zu & za, ze, zi, zo, zu \\
\hline ja, je/ge, ji/gi, jo, ju & {$[\mathrm{xa}, \mathrm{xe}, \mathrm{xi}, \mathrm{xo}, \mathrm{xu}]$} & ja, je, ji, jo, ju & ja, je, ji, jo, ju \\
\hline ga, gue, gui, go, gu & [ga, ge, gi, go, gu] & ga, g̃e, g̃i, go, gu & ga, ge, gi, go, gu \\
\hline Letra $\mathrm{k}$ & {$[\mathrm{k}]$} & Eliminar; utilizar c & Íd. \\
\hline Letra $\mathrm{q}$ & {$[\mathrm{k}]$} & Eliminar; utilizar c & Íd. \\
\hline Letra $\mathrm{h}$ & {$[\varnothing]$} & Eliminar & Íd. \\
\hline Letra $\mathrm{x}$ & {$[\mathrm{x}],[\mathrm{ks}]$} & $\mathrm{j}, \mathrm{cs}$ & Íd. \\
\hline
\end{tabular}

Tabla 2. Resumen de la propuesta ortográfica para la lengua española de Hervás y Panduro (1795).

Como vemos, entonces, el jesuita ofrece una solución para los siguientes problemas ortográficos:

- La letra h, que desaparece

- La letra $\mathrm{x}$, que desaparece sustituida por su sonido: cs para [ks], j para [x]

- Las letras k y q, [k], porque se simplifican en la letra c

- El par de letras b/v para [b], porque simplifica en la letra v

- El par de letras c/z para [q], porque simplifica en la letra z

- El par de letras g/j para [x], porque simplifica en la letra j

Sin embargo, Hervás no parece darse cuenta, cuando sugiere la escritura con virgulilla de las letras c o g, de que comete un error muy parecido al que quiere evitar: esto es, ańadir un símbolo gráfico a una letra que representa el mismo sonido que otra letra sin ese símbolo gráfico. En resumidas cuentas, vuelve a proponer dos símbolos para el mismo sonido: c y ̃ para [k], y g y $\tilde{\mathrm{g}}$ para $[\mathrm{g}]$. En lo que a reformas se refiere, parece innecesaria esa rayita cuando de lo que se trata es de simplificar el sistema ortográfico, por lo que es difícil de entender la propuesta. Pero no contento con esta opción, propone además el uso de otra rayita sobre la letra 1 cuando esta se dobla en la ortografía latina y para diferenciarla de la que representa el sonido $[K]$ :

Además de estas correcciones fáciles, se debe hacer otra que es necesaria é igualmente facil. Esta consiste en poner una rayita á la letra l, quando se haya de doblar, como se dobla en las palabras latinas allego, allegoria, \&c. las quales se deben leer como si estuvieran escritas así: al-lego, al-legoria: esto es, la primera 1 se pronuncia con la a, como si se pronunciára la sílaba al, y la segunda 1 se pronuncia con la e. Este modo de pronunciar no se dá en la ortografía española, porque en ella la 1 doblada forma una letra diferente de la 1 simple, y tiene su sonido propio y diverso del sonido de la 1 . Para no alterar la ortografía hasta ahora usada, en la que la l doblada tiene su sonido 
particular, como en las palabras llegar, allegar, y para poder dar á la 1 doblada el sonido propio que le corresponde, como en las palabras latinas allego, allegoria, convendrá usar una $l$ con una rayita encima de ella, siempre que se quiera notar el sonido propio de la 1 doblada á distincion del sonido que se dá en español á las sílabas lla, lle, lli, llo, llu. (Hervás 1795: 207-208)

Y con respecto a las consonantes dobladas, Hervás realiza una última consideración:

En la explicacion, que del alfabeto espańol acabo de hacer, no he hablado del sonido vocal correspondiente á las consonantes dobladas; porque de éstas solamente tres, que son c, n, r, se doblan en las palabras españolas, y unicamente la r doblada tiene sonido particular y propio. En la pronunciacion vulgar ó comun, las palabras en que se doblan las letras c, n (como en leccion, innocente) estas letras se suelen proferir, como si no estuvieran dobladas. En el idioma latino es muy comun la duplicacion de las consonantes, cuya pronunciacion (de que se hablará despues en el capítulo 14) deben saber los maestros que lo enseñan. En España el latin se pronuncia imperfectísi-mamente, porque en las escuelas no se enseña la pronunciacion de las consonantes dobles, y de la letra $\mathrm{m}$ final, que no se usan en las palabras españolas. La buena pronunciacion del latin sirve para aprender á hablar bien las lenguas europeas mas doctas, pues en ellas es comun el uso de las dichas consonantes dobladas. (Hervás 1795: 209)

Para terminar su propuesta, entiende que su sistema es sencillo y útil, y que responde al «escribo como hablo»:

Con estas pocas y facilísimas correcciones, sin detrimento de la ortografía antigua, se podría introducir la nueva con que el mas idiota que supiese escribir, pudiese escribir bien, escribiendo como habla. Las nuevas correcciones facilitarian el modo de escribir con ortografia sin necesidad de estudiarla, y sin que se dexase de entender la antigua en los manuscritos y libros impresos. Muchos franceses han escrito sobre la necesidad de reformar su ortografía, y han propuesto medios inasequibles: el que yo propongo es facil de efectuarse, y es utilísimo. (Hervás 1795: 208)

Independientemente de modas, tendencias o propuestas reformistas o conservadoras en lo que a la ortografía del español se refiere, podemos reconocer en la propuesta de Hervás al menos dos cosas: su necesario y estricto carácter aplicado -es decir, se propone para que funcione- $\mathrm{y}$ el hecho de que deriva directamente de la práctica de la enseñanza de la pronunciación. Aunque llegue al mismo lugar que muchos gramáticos, ortógrafos o maestros de primeras letras, su originalidad estriba en la diferencia cualitativa nacida de la distinta forma de instruir a personas oyentes y a personas sordas: las primeras viajan de lo oral a lo escrito; las segundas, de lo escrito a lo oral ${ }^{11}$.

11. Desde el siglo XVIII, muchas propuestas de reformas nacen al calor de la instrucción infantil o primaria: ciertos maestros de primeras letras o ciertas corrientes pedagógicas, cuando empiezan a cuestionarse las bases académicas de la escritura, comienzan a tener en cuenta algunos aspectos más ligados a la oralidad (o menos apegados a la tradición de la escritura) ya que comienza a concebirse una instrucción más fundamentada en la práctica. 


\section{ReFLEXiOnes FinALES}

Creo que lo más interesante de la propuesta ortográfica de Hervás reside en la misma razón de dicha propuesta: la enseñanza de la pronunciación. Quizá puede parecer un contrasentido pero, al menos en el caso de la instrucción a personas sordas, ha quedado claro que lo escrito conduce necesariamente hacia lo oral. Y esta puede ser la razón por la que podemos pensar que Hervás no propone exactamente una reforma ortográfica de la lengua española sino, sencillamente, una reforma de la escritura.

Es evidente que lo que nos ofrece el jesuita en el Tomo II de su Escuela Española de Sordomudos no es una ortografía al uso puesto que no hay divisiones canónicas ni canon: no hay forma, o género, en el fondo. Por más que en su trabajo exponga cuestiones interesantes $-\mathrm{e}$, incluso a veces de una manera más perspicaz que sus contemporáneos- relativas a la gramática o a la ortografía, creo que no puede afirmarse con rotundidad que Hervás sea un gramático o un ortógrafo -al menos dentro del canon-. Pero por esto mismo sí podremos decir que pueda ser un lingüista en el sentido actual del término, en tanto en cuanto su objeto de estudio tiene más que ver con problemas relativos a la comunicación y al lenguaje y no tanto a la descripción de una lengua en particular: en este caso concreto, sin duda, las aportaciones de Hervás a este respecto en el resto de $E E S$ son muy relevantes, interesantes, originales y, hasta cierto punto, excepcionales en el panorama filológico español de la época.

Con todo, hay dos apuntes originales en la propuesta de Hervás que querría señalar aquí y que me permitirán reflexionar acerca del estatus de disciplinas como la ortografía o la gramática. Son los dos siguientes:

1. En primer lugar, es interesante mencionar -independientemente de su valor pedagógico- la trascendencia teórica que subyace al uso (en la ortografía, en la instrucción) de combinaciones silábicas en vez de letras únicas (o únicamente sistemas de letras o sonidos). Algunas descripciones ortográficas, las que no presentan una relación de las combinaciones posibles de elementos, realizan descripciones estrictamente paradigmáticas del sistema de una lengua y, pocas veces -o nunca-, mencionan o relacionan las sintagmáticas (es decir, las combinaciones posibles de sonidos). En ellas no suele mencionarse qué sonidos pueden aparecer combinados con otros o en qué posiciones. Si seguimos con el razonamiento, en puridad deberíamos decir que la descripción del sistema fonético de una lengua pertenecería a una sintaxis, puesto que debe describir cómo se relacionan -o cómo deben relacionarse- los sonidos en la cadena hablada dentro de las normas establecidas por el sistema de la lengua. Para Hervás y otros instructores, resulta sencillo y útil enseñar las combinaciones en vez de mostrar el sistema; y esta puede ser una de las razones por las que las descripciones fonéticas de Hervás o Silvestri sean más precisas que la de muchos de sus contemporáneos (Battaner \& Dovetto 2013). 
2. El segundo está relacionado con el hecho de plantear problemas ortográficos partiendo de la enseñanza de la pronunciación, precisamente cuando se discute si la ortografía debe quedar fuera de la gramática porque la primera se refiere, en principio, a la forma de escribir correctamente y la segunda, en general, a la forma de hablar correctamente.

Ciertamente a veces la Ortografía se deja fuera de la Gramática aduciendo -entre otras razones- que la primera sólo sirve para escribir. Y es este un argumento peculiar porque, tradicionalmente, se ha señalado a la gramática como la ciencia de «hablar bien». Pero hemos de reconocer que las gramáticas se refieren básicamente a "escribir bien» -no hace falta que mencione las diferencias reales -gramaticales, normativas- entre la lengua oral y la escrita-. En cambio, la ortografía, que en realidad es aquella disciplina que reflexiona acerca de la relación entre el sonido y la grafía y acerca de sus combinaciones, y que es aquella que esconde toda la base del conocimiento de una lengua y de sus palabras -i.e. la morfo-fonología-, se define reduciéndola a las reglas de la correcta escritura. ¿Qué es, por tanto, lo que ha expuesto Hervás? Una reforma de la escritura no para escribir, sino para pronunciar. En este punto podemos encontrarnos, entonces, ante una paradoja singular: y es que parece que, en lo fundamental, ni la ortografía trata de lo escrito ni la gramática de lo hablado. Es al revés.

\section{Bibliografía}

\section{Fuentes primarias}

Donnino, A. G., L'arte di far parlare i sordomuti dalla nascita e l'abbate Tommaso Silvestri. Memorie, Roma, Mario Armanni, 1889.

L'Épée, Charles Michel (abbé de), Institution des sourds et muets par la voie des signes méthodiques, París, Nyon l'Aîné, 1776.

Hervás y Panduro, Lorenzo, Historia de la vida del hombre. Tomo 1: concepción, nacimiento infancia y niñez del Hombre, Madrid, Imp. de Aznar, 1789-1799.

Hervás y Panduro, Lorenzo, Escuela española de sordomudos, o Arte para enseñarles a escribir y hablar el idioma español, dividida en dos tomos, Madrid, Imprenta Real y Villalpando, 1795.

Hervás y Panduro, Lorenzo, Catálogo de las lenguas de las naciones conocidas y enumeración, división y clases de estas según la diversidad de sus idiomas y dialectos, Madrid, Administración del Real Arbitrio de Beneficencia, 1800-1805.

\section{Fuentes secundarias}

Battaner Moro, Elena, «La investigación sobre ortografía, fonética y fonología en la tradición lingüística española», Bartardín, T., Rivas, M. (eds.) y García Martín, J. M. ${ }^{a}$ (bajo la dir.), Estudios de historiografía lingüistica, Cádiz, Universidad de Cádiz, 2009, p. 27-44.

Battaner Moro, Elena, «Sordomudística e Historia de la fonética en la historiografía lingüística española: el efecto Bonet», Beiträge zur Geschichte der Sprachwissenschaft, vol. 21, n 2, 2011, p. 167-178. 
Battaner Moro, Elena, «Lenguas y signos: influencia francesa en la Escuela Española de Sordomudos de Lorenzo Hervás y Panduro», Battaner, Elena \& Calvo, Vicente et Peña, Palma, Historiografía lingüistica: lineas actuales de investigación, Münster, Nodus Publikationen, 2012.

Battaner Moro, Elena \& Dovetto, Francesca M., «La educación lingüística de personas sordas en el siglo XVIII. Líneas de convergencia entre las escuelas española e italiana", Romanistik in Geschichte und Gegenwart, n 19:1, 2013.

Corts Giner, María Isabel \& García Jiménez, Eduardo, «La enseñanza de los sordomudos en España en el siglo XVIII a través de la obra de Hervás y Panduro», dans Educación e Ilustración en España. III Coloquio de Historia de la Educación. Ed. por el Departamento de Historia de la Educación Comparada e Historia de la Educación, Barcelona, Universidad de Barcelona, 1984, p. 68-76.

Esparza, Miguel Ángel (dir.) \& Battaner, Elena \& Calvo, Vicente \& Álvarez, Adrián et Rodríguez, Susana, Bibliografía Temática de Historiografía Lingüistica Española. Fuentes Secundarias, Hamburgo, Buske, 2008.

Esteve Serrano, Abraham, Estudios de teoría ortográfica del español, Murcia, Departamento de Lingüística General y Crítica Literaria, 1982.

Hassler, Gerda, "Las lenguas del Nuevo Mundo en las teorías lingüísticas del siglo XVIII», Escavy, Ricardo et Hernández, José M. et Roldán, Antonio, Actas del Congreso Internacional de Historiografía Lingüistica. Nebrija V Centenario, Murcia, Escavy \& Hernández Terrés \& Roldán, 1994, vol. II, p. 115-125.

Maquieira Rodríguez, Marina, «Las ortografías no académicas del siglo XVIII (1700)1835», Gómez Asencio, José J., El castellano y su codificación gramatical. Volumen III. De 1700 a 1835, Valladolid, Fundación Instituto Castellano y Leonés de la Lengua, 2011, p. 493-546.

Martínez Alcalde, M. José, (comp.), Textos Clásicos sobre la Historia de la Ortografía Castellana, Madrid, Publicaciones de la Fundación Histórica Tavera, 1999.

Martínez Gavilán, M. ${ }^{a}$ Dolores, «La sílaba en la teoría gramatical del siglo XVII», Estudios Humanísticos. Filología 7, 1985, p. 125-144.

Poch Olivé, Dolors, «Lorenzo Hervás y Panduro y la reeducación de sordomudos: contribución al estudio de un capítulo de la historia de la lingüística española», Fernández, Jesús et al., Lingüistica para el siglo XXI: III Congreso de Lingüistica General. Salamanca, 23-25 de marzo de 1998, Salamanca, Universidad de Salamanca, 1999, p. 1299-1307.

Rosenfeld, Sophia, A Revolution in Language: The Problem of Signs in Late EighteenthCentury France, Stanford, Stanford University Press.

Sánchez Pérez, José, 1936, Estudios sobre Lorenzo Hervás y Panduro (1735-1809). II. La Escuela española de Sordomudos, Madrid, Asociación Nacional de Historiadores de la Ciencia Española, 2001.

Tovar, Antonio, «Hervás y las lenguas indias de América del Norte», Revista Española de Lingüistica 11, 1981, p. 1-11. 
